\title{
Adensamento da Beterraba no Manejo de Plantas Daninhas ${ }^{1}$
}

\author{
Increased Beet Density in Weed Management
}

CARVALHO, L.B. ${ }^{2}$ e GUZZO, C.D. ${ }^{3}$

\begin{abstract}
RESUMO - O objetivo deste trabalho foi verificar o efeito do adensamento da semeadura na capacidade de supressão da cultura da beterraba sobre a comunidade infestante. Os tratamentos constituiram-se de 12 periodos semanais crescentes de convivência e controle das plantas daninhas, a partir da segunda semana após a semeadura, submetidos a duas densidades populacionais da cultura (40 e 50 plantas $\mathrm{m}^{-2}$ ). Avaliou-se o acúmulo de massa seca pelas plantas daninhas em cada periodo e a estimativa da época e extensão dos periodos críticos de interferência das plantas daninhas em função da produtividade comercial da cultura. Observou-se menor acúmulo de massa seca pelas plantas daninhas quando a cultura foi adensada, sendo a diferença média no acúmulo de 17 e 30\% para periodos de convivência e controle, respectivamente. O período critico de prevenção à interferência foi menor na cultura adensada (11 dias) em relação à não-adensada (22 dias). O adensamento de semeadura da cultura da beterraba proporcionou aumento na capacidade de supressão da cultura sobre a comunidade infestante, afetando o crescimento e a época e extensão dos períodos críticos de interferência das plantas daninhas, podendo ser usado como ferramenta eficaz no manejo da flora invasora.
\end{abstract}

Palavras-chave: Beta vulgaris, comunidade infestante, manejo cultural.

ABSTRACT - The aim of this research was to evaluate the effect of increased beet density on the capacity of beet plants to suppress weeds. The treatments were twelve weedy and weed-free increased periods submitted to two beet plant densities (40 and 50 plants $\mathrm{m}^{-2}$ ). Extension of weed interference was one week and time evaluation started in the second week after sowing. Weed dry mass accumulation for each period and estimate of time and extension of weed interference critical periods based on beet marketable yield were evaluated. Less weed dry mass accumulation was observed for increased beet density. The average percent difference of weed dry mass accumulation between densities was 17 and $30 \%$ underweedy and weed-free periods, respectively. The critical period of weed interference prevention was shorter for increased beet density (11 days) than for 40 plants $\mathrm{m}^{-2}$ beet density (22 days). Thus, increased beet density increased beet plant capacity to suppress weeds. Thus, weed growth and time and extension of weed interference critical periods were affected. Increased beet density can be used as an efficient tool for weed management.

Keywords: Beta vulgaris, cultural management, weed community.

\section{INTRODUÇÃO}

As comunidades vegetais são muito influenciadas por fatores ecológicos, que, direta ou indiretamente, podem prejudicar seu cresci- mento e desenvolvimento. Um dos fatores que mais afetam negativamente a produtividade das culturas agrícolas é a interferência imposta pelas plantas daninhas, sendo o grau dessa interferência influenciado principalmente pe-

Recebido para publicação em 19.6.2007 e na forma revisada em 4.1.2008.

2 Doutorando do Programa de Pós-Graduação em Produção Vegetal da FCAV/UNESP, NEPEAM, via de Acesso Prof. Paulo Donato Castellane, s/n, 14884-900, Jaboticabal, SP, <agrolbcarvalho@gmail.com>; ${ }^{3}$ Engenheiro-Agrônomo. 
lo período em que plantas daninhas e cultivadas conjuntamente disputam os recursos limitados do meio (Pitelli, 1985).

A convivência das plantas daninhas com a cultura da beterraba (Beta vulgaris) resulta em perdas significativas na produção (Brito, 1994). A produtividade de raízes da beterraba pode ser reduzida em mais de $80 \%$ quando a comunidade infestante convive com a cultura durante todo o ciclo agrícola (Hewson \& Roberts, 1973; Scott et al., 1979; Schweizer, 1981; Tozani et al., 1997). Contudo, essa redução pode chegar a 100\% (Brito, 1994; Horta et al., 2004; Kavaliauskaitë \& Bobinas, 2006), dependendo das condições ambientais e de manejo da cultura.

A interferência das plantas daninhas em agroecossistemas olerícolas é extremamente elevada, pelo fato de as áreas destinadas ao cultivo passarem por exploração intensiva do solo, com alta freqüência de mobilização, elevada taxa de fertilização e pequena restrição hídrica (Pitelli \& Durigan, 1984). Dessa forma, ocorrem elevadas populações de plantas daninhas de alta agressividade (Pitelli, 1984; Pereira, 1987).

Estudos a respeito da influência de comunidades infestantes sobre espécies cultivadas têm sido realizados, principalmente, com a finalidade de determinar os períodos críticos de interferência das plantas daninhas sobre a produtividade das culturas agrícolas. Esses períodos foram definidos por Pitelli \& Durigan (1984) como periodo anterior à interferência (PAI), período total de prevenção à interferência (PTPI) e período crítico de prevenção à interferência (PCPI), os quais, segundo Pitelli (1985), refletem a adequação das condições de implantação e manejo das culturas. De acordo com Kavaliauskaitë \& Bobinas (2006), período crítico de interferência refere-se aos estádios de crescimento das culturas que são mais vulneráveis à competição imposta pelas plantas daninhas; na prática, é definido como o número de semanas em que a cultura deve ser mantida livre da presença de plantas daninhas para prevenir perdas de produtividade maiores que 5\% (Hall et al., 1992; Van Acker et al., 1993; Knezevic et al., 1994). Portanto, qualquer fator que prolongue o PAI e/ou reduza o PTPI poderá amenizar os efeitos da interferência imposta pela comunidade infestante.

O manejo adequado da comunidade infestante é fator primordial para reduzir a interferência das plantas daninhas sobre a produtividade das culturas agrícolas. Segundo Deuber et al. (2004), esse é um dos fatores determinantes para alcançar boas produções de culturas olerícolas.

Em áreas de olericultura, o manejo das plantas daninhas é realizado geralmente por meio físico, mecânico e/ou químico, tornandose, em qualquer um dos casos, oneroso ao produtor. Como alternativa, tem-se o manejo cultural, na maioria das vezes de menor custo, que, se aplicado adequadamente, apresenta alta eficiência. Como ferramenta para esse tipo de manejo pode-se adotar o adensamento da semeadura, visto que o arranjo espacial das plantas cultivadas constitui fator relevante na definição das relações de competição destas com as plantas daninhas (Fischer \& Miles, 1973; Norris et al., 2001).

Segundo Velini (1997), a melhor maneira de controlar as plantas daninhas é por meio da própria cultura. Assim, o principal objetivo deve ser dar vantagem às plantas cultivadas em relação às daninhas, já que todos os aspectos que influenciam favoravelmente a velocidade de crescimento da cultura são de fundamental importância para minimização do período de interferência (Horta et al., 2004). Portanto, por meio do adensamento da semeadura busca-se potencializar a capacidade de supressão da cultura sobre a comunidade infestante, promovendo sombreamento precoce do solo com a finalidade de afetar negativamente a germinação, o crescimento e o desenvolvimento das plantas daninhas.

Trabalhos relacionados ao adensamento de semeadura da cultura da beterraba como ferramenta no manejo da comunidade infestante não foram encontrados na literatura. Esse tipo de trabalho tem sido realizado com mais freqüência em culturas anuais de cereais. De maneira geral, o adensamento da semeadura pode promover supressão da comunidade infestante e conseqüente redução do acúmulo de massa seca pelas plantas daninhas, conforme observado por Medd et al. (1985), Norris et al. (2001), Weiner et al. (2001), 
Balbinot Júnior \& Fleck (2005), Olsen et al. (2005a,b 2006) e Hock et al. (2006). O adensamento pode influenciar também a época crítica para controle das plantas daninhas, conforme verificado por Knezevic et al. (2003) e Norsworthy \& Oliveira (2004).

Enfatiza-se, por outro lado, que alguns estudos indicam que o arranjo espacial das plantas pode não interferir na competitividade da cultura, e o efeito desse arranjo é dependente de fatores como: espécie cultivada, características morfofisiológicas dos genótipos, espécies daninhas presentes na área e época relativa de sua emergência, além de condições ambientais, principalmente temperatura, radiação solar e regime pluvial (Balbinot Júnior \& Fleck, 2005).

O objetivo deste trabalho foi verificar o efeito do adensamento da semeadura na capacidade de supressão da cultura da beterraba sobre a comunidade infestante.

\section{MATERIAL E MÉTODOS}

O experimento foi conduzido em área experimental da FCAV/UNESP, campus de Jaboticabal, entre julho e outubro de 2006 . O solo foi caracterizado como Latossolo Vermelho eutrófico de textura argilosa, com características químicas de $\mathrm{pH}\left(\mathrm{CaCl}_{2}\right)$ igual a 5,$6 ; 25 \mathrm{~g} \mathrm{dm}^{3}$ de $\mathrm{MO} ; 87 \mathrm{mg} \mathrm{dm}^{-3}$ de P (resina); e 4, 43, 16 e $25 \mathrm{mmol}_{\mathrm{c}} \mathrm{dm}^{-3} \mathrm{de} \mathrm{K}^{+}, \mathrm{Ca}^{2+}, \mathrm{Mg}^{2+} \mathrm{e} \mathrm{H}^{+} \mathrm{Al}^{3+}$, respectivamente.

A correção química do solo foi baseada em recomendação de Trani et al. (1997). A acidez foi corrigida com a aplicação de $590 \mathrm{~kg} \mathrm{ha}^{-1}$ de calcário com PRNT de 120,8\%, em área total. As adubações minerais foram realizadas sobre os canteiros, sendo a de plantio efetuada com $240 \mathrm{~kg} \mathrm{ha}^{-1}\left(40 \mathrm{~g} \mathrm{~m}^{-2}\right)$ da formulação 04-30-16, mais $12 \mathrm{~kg} \mathrm{ha}^{-1}\left(2 \mathrm{~g} \mathrm{~m}^{-2}\right)$ de sulfato de amônia, $24 \mathrm{~kg} \mathrm{ha}^{-1}\left(4 \mathrm{~g} \mathrm{~m}^{-2}\right)$ de superfosfato simples e $12 \mathrm{~kg} \mathrm{ha}^{-1}\left(2 \mathrm{~g} \mathrm{~m}^{-2}\right)$ de bórax; e a de cobertura, com $90 \mathrm{~kg} \mathrm{ha}^{-1}\left(15 \mathrm{~g} \mathrm{~m}^{-2}\right)$ de uréia e $36 \mathrm{~kg} \mathrm{ha}^{-1}$ $\left(6 \mathrm{~g} \mathrm{~m}^{-2}\right)$ de cloreto de potássio, parcelada em três vezes iguais, 15, 30 e 50 dias após a semeadura (DAS).

A semeadura foi realizada no dia 4 de julho de 2006, e o desbaste, em duas épocas: aos 10 DAS e quando as plantas apresentaram de cinco a seis folhas (repasse).
A área foi irrigada por aspersão, uma vez por dia até 50 DAS e, após esse período, duas vezes por semana.

O experimento foi conduzido no delineamento de blocos ao acaso, em esquema fatorial $2 \times 2 \times 12$, com três repetições. Os fatores empregados foram duas densidades populacionais da cultura da beterraba ( 40 e 50 plantas $\mathrm{m}^{-2}$ ), dois grupos de manejo das plantas daninhas (periodos iniciais de convivência e de controle) e 12 períodos de interferência das plantas daninhas sobre a cultura $(14,21,28,35,42,49$, $56,63,70,77,84$ e 91 DAS).

Os tratamentos experimentais constituíram-se de dois grupos de manejo das plantas daninhas, ou seja, 12 periodos crescentes de convivência ou controle, submetidos a duas densidades populacionais. No primeiro grupo, a cultura permaneceu na presença das plantas daninhas desde a semeadura até o respectivo período do seu ciclo de desenvolvimento (períodos de convivência). Após cada período, as plantas daninhas foram removidas das parcelas por meio de capinas manuais até a colheita. No segundo grupo, a cultura permaneceu na ausência de plantas daninhas desde a semeadura até o respectivo período do seu ciclo de desenvolvimento (períodos de controle). Após esses periodos, as plantas daninhas conviveram com a cultura até a colheita.

As parcelas experimentais foram compostas por quatro linhas de semeadura espaçadas de $0,25 \mathrm{~m}$ (40 plantas $\left.\mathrm{m}^{-2}\right)$ ou por cinco espaçadas de $0,20 \mathrm{~m}$ (50 plantas $\left.\mathrm{m}^{-2}\right)$. O espaçamento adotado entre plantas foi de $0,10 \mathrm{~m}$. O comprimento das parcelas foi de $1,20 \mathrm{~m}$, em que $0,10 \mathrm{~m}$ de cada extremidade das parcelas foi considerado bordadura, sendo, portanto, a área útil das parcelas de $1,00 \mathrm{~m}^{2}$.

$\mathrm{Na}$ comunidade infestante, estimou-se o acúmulo de massa seca por meio de uma amostragem das plantas daninhas, dentro da área útil das parcelas, no final de cada período de convivência. Nos períodos de controle, essas amostragens foram realizadas por ocasião da colheita. Para isso, foi utilizado um quadro de ferro com dimensões de 0,5 x 0,5 m. Depois de coletadas, as plantas foram lavadas, deixadas secar à sombra e levadas à estufa de circulação forçada de ar a $60{ }^{\circ} \mathrm{C}$, por pelo menos 96 horas. Posteriormente, foram pesadas em 
balança de precisão de $0,01 \mathrm{~g}$, sendo extrapolados os dados de massa seca acumulada para $\mathrm{g} \mathrm{m}^{-2}$.

Avaliou-se, também, a diferença percentual do acúmulo de massa seca pelas plantas daninhas submetidas às duas densidades populacionais da cultura da beterraba. Para isso, comparou-se o acúmulo de massa seca entre as densidades populacionais em cada periodo de avaliação e obteve-se a diferença média, considerando o acúmulo total ao longo do ciclo.

A cultura foi colhida aos 91 DAS, quando 90\% das raízes de beterraba apresentavam diâmetro superior a $5 \mathrm{~cm}$. Após a colheita, as raízes foram lavadas, deixadas secar à sombra, medidas em diâmetros transversais, selecionadas e pesadas em balança de precisão de $0,1 \mathrm{~g}$. Os dados de produtividade comercial foram extrapolados para t ha ${ }^{-1}$.

$\mathrm{Na}$ seleção das raízes foram empregados critérios baseados em Horta et al. (2004). As raízes menores que $4 \mathrm{~cm} \mathrm{e}$ / ou com podridões, rachadas, quebradas ou com qualquer outro dano foram descartadas, e aquelas de 4 ou maiores que $4 \mathrm{~cm}$ foram consideradas do tipo comercial.

Para determinação do PAI (em função dos períodos de convivência) e do PTPI (em função dos períodos de controle), os dados de produtividade comercial foram analisados e processados separadamente dentro de cada grupo de manejo das plantas daninhas e submetidos à análise de regressão pelo modelo sigmoidal de Boltzmann, considerando-se aceitável 5\% de perda na produtividade. Esse modelo foi adaptado por Kuva et al. (2000) e obedece à equação:

$$
y=\frac{\left(A_{1}-A_{2}\right)}{1+e^{\left(x-x_{0}\right) / d x}}+A_{2}
$$

em que y expressa a produtividade comercial de beterraba em função dos períodos de convivência ou de controle; $x$, o limite superior do período de convivência ou de controle; $\mathrm{x}_{0}$, o limite superior do período de convivência ou de controle, que corresponde ao valor intermediário entre produtividade máxima e mínima; $\mathrm{A}_{1}$, a produtividade máxima obtida nas parcelas mantidas em controle durante todo o ciclo; $\mathrm{A}_{2}$, a produtividade mínima obtida nas parcelas mantidas em convivência durante todo o ciclo;
$A_{1}-A_{2}$, a perda de produtividade; e dx, o parâmetro que indica velocidade de perda ou ganho de produtividade.

Quando o PTPI for mais prolongado que o PAI, o PCPI tem início ao final do PAI e término ao final do PTPI (Pitelli \& Durigan, 1984), e as plantas daninhas devem ser controladas durante todo o PCPI (Pitelli \& Pitelli, 2004). Quando o PAI suplantar o PTPI, o PCPI resume-se a um único controle das plantas daninhas entre os finais do PTPI e do PAI (Pitelli \& Pitelli, 2004).

\section{RESULTADOS E DISCUSSÃO}

As populações de plantas daninhas que infestaram a cultura da beterraba foram Amaranthus viridis, Bidens pilosa, Emilia sonchifolia, Galinsoga parviflora, Parthenium hysterophorus, Coronopus didymus, Lepidium virginicum, Cyperus rotundus, Brachiaria plantaginea, Digitaria nuda, Eleusine indica, Oxalis latifolia, Portulaca oleracea, Nicandra physaloides e Solanum americanum. Dentre elas, as espécies que se destacaram foram A. viridis, C. didymus, G. parviflora, $N$. physaloides e $S$. americanum.

Todas as espécies encontradas podem ser consideradas ruderais de acordo com critérios de Grime (1979), por apresentarem rápida germinação, curto ciclo de desenvolvimento, rápida produção de diásporos e elevada partição de recursos nas estruturas de reprodução, podendo ser extremamente agressivas na competição com as culturas. Dentre elas, $C$. didymus mostrou fortes evidências desse caráter ruderal, assim como observado por Pitelli (1987) e Soares et al. (2003).

Segundo Pitelli (1987), de maneira geral, as áreas de olericultura são adequadas ao desenvolvimento de populações ruderais, devido à grande disponibilidade de recursos no meio, à alta freqüência dos distúrbios do solo e à grande desuniformidade espacial na ocupação da área.

O menor acúmulo de massa seca pelas plantas daninhas, quando a semeadura da cultura da beterraba foi adensada, pode ser observado na Figura 1, tanto nos períodos crescentes de convivência como nos de controle. Isso somente não foi verificado aos 14, 21 e 28 dias 

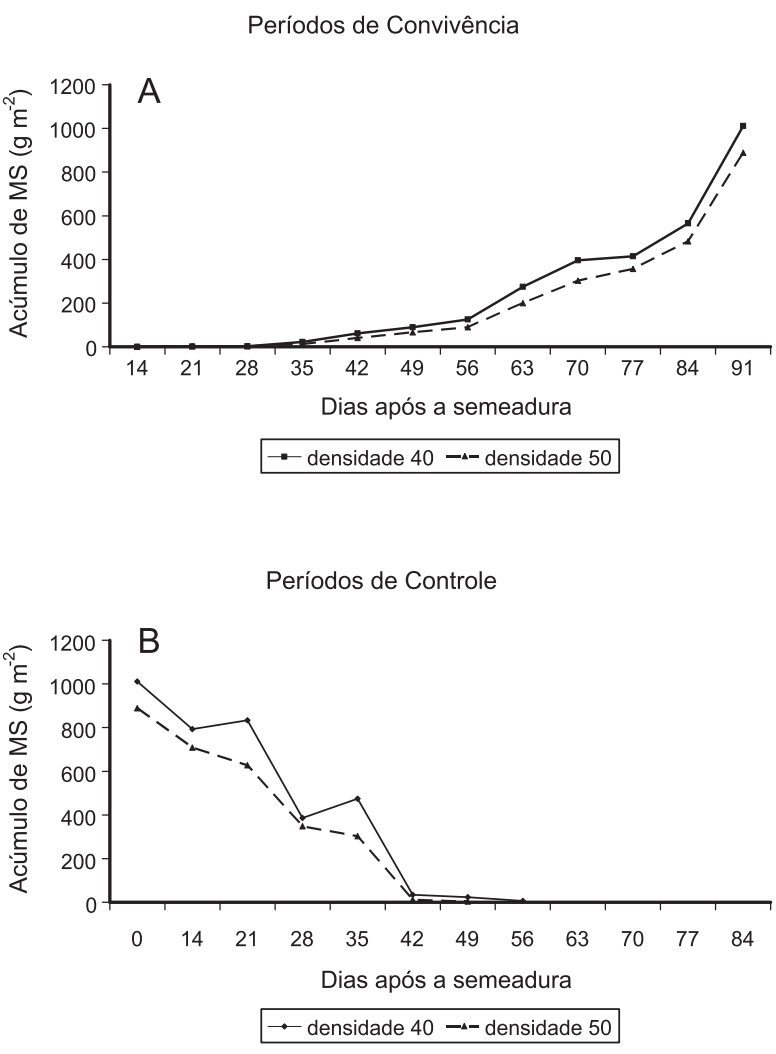

Figura 1 - Acúmulo de massa seca (MS) pelas comunidades infestantes que infestaram a cultura da beterraba, em função da densidade populacional da cultura (40 e 50 plantas $\mathrm{m}^{-2}$ ). FCAV/UNESP, Jaboticabal-SP, 2006. A - Períodos de convivência; B - períodos de controle.

de convivência, o que pode ter ocorrido devido a um maior fluxo de emergência de plantas daninhas nos períodos iniciais de convivência, proporcionando maior acúmulo de massa seca dessas plantas, quando a cultura foi adensada.

A tendência geral foi de aumento contínuo no acúmulo de massa seca pelas plantas daninhas nos períodos crescentes de convivência (Figura 1A) e diminuição nos de controle (Figura 1B). As plantas daninhas que cresceram infestando a cultura da beterraba estabelecida por 40 e 50 plantas $\mathrm{m}^{-2}$ acumularam, respectivamente, $1.010,81$ e $888,61 \mathrm{~g}$ de massa seca, ao final dos períodos crescentes de convivência. Após 49 e 56 dias de controle (50 e 40 plantas $\mathrm{m}^{-2}$, respectivamente), a comunidade infestante foi totalmente suprimida pela cultura.

A diferença percentual do acúmulo de massa seca pelas plantas daninhas pode ser observada na Tabela 1. A cultura adensada promoveu supressão no acúmulo médio de massa seca aproximadamente $17 \%$ maior nos períodos crescentes de convivência e 30\% maior nos de controle, quando comparada à cultura estabelecida por 40 plantas $\mathrm{m}^{-2}$. A diferença negativa observada nos períodos de 14, 21 e 28 dias de convivência indica que as plantas daninhas que infestaram a cultura adensada acumularam mais massa seca em relação àquelas que cresceram sob 40 plantas $\mathrm{m}^{-2}$. Esse fato provavelmente ocorreu devido ao fluxo germinativo das plantas daninhas, conforme supracomentado.

Esses resultados evidenciam que o adensamento da semeadura promoveu aumento na capacidade de supressão da cultura da beterraba sobre a comunidade infestante, afetando o crescimento das plantas daninhas. Essas evidências podem ser comprovadas analisando-

Tabela 1 - Diferença percentual do acúmulo de massa seca das plantas daninhas, em função da densidade populacional da cultura da beterraba (40 e 50 plantas $\mathrm{m}^{-2}$ ). FCAV/UNESP, Jaboticabal-SP, 2006

\begin{tabular}{|c|c|c|}
\hline \multirow[t]{2}{*}{ DAS** } & \multicolumn{2}{|c|}{$\begin{array}{c}\text { Diferença no acúmulo de massa seca } \\
\qquad(\%)\end{array}$} \\
\hline & Convivência & Controle \\
\hline 0 & & 12,09 \\
\hline 14 & $-6,25^{*}$ & 10,62 \\
\hline 21 & $-9,88^{*}$ & 24,72 \\
\hline 28 & $-10,20 *$ & 10,00 \\
\hline 35 & 43,17 & 36,25 \\
\hline 42 & 35,45 & 62,69 \\
\hline 49 & 26,07 & 82,46 \\
\hline 56 & 28,75 & - \\
\hline 63 & 27,47 & - \\
\hline 70 & 23,62 & - \\
\hline 77 & 13,89 & - \\
\hline 84 & 14,54 & - \\
\hline 91 & 12,09 & - \\
\hline Média & 16,56 & 29,85 \\
\hline
\end{tabular}

* Diferença negativa indica que o acúmulo de massa seca foi maior em densidade populacional de 50 plantas $\mathrm{m}^{-2}$; ** DAS significa dias após a semeadura. 
se a Figura 1A, na qual, a partir de 35 DAS, é evidente o menor acúmulo de massa seca pelas plantas daninhas que infestaram a cultura estabelecida por 50 plantas $\mathrm{m}^{-2}$, e na Tabela 1 (periodos de convivência), onde se verifica a diferença percentual entre esses acúmulos. Da mesma maneira, na Figura 1b observa-se o menor acúmulo de massa seca pela comunidade infestante na cultura estabelecida por 50 plantas $\mathrm{m}^{-2}$; a supressão total do crescimento das plantas daninhas ocorreu sete dias antes em relação à cultura estabelecida por 40 plantas $\mathrm{m}^{-2}$. Esse fato também fica evidente na Tabela 1 (períodos de controle), onde se verifica a diferença percentual entre esses acúmulos. Portanto, o adensamento da semeadura proporcionou à cultura maior capacidade de supressão das plantas daninhas.

Segundo Charles-Edwards (1986) e Hay \& Walker (1989), quando fatores extrínsecos à cultura (plantas daninhas, insetos-praga, doenças, condições de solo, água e nutrientes) não são limitantes, a produção de matéria seca de uma cultura é função da radiação absorvida pelo dossel, da eficiência média de conversão da radiação absorvida em matéria seca e da partição dessa matéria seca entre as partes úteis e o restante da planta. A redução do espaçamento entre fileiras de plantio propicia aumento da interceptação de luz pelo dossel das plantas cultivadas; a cultura ocupa o espaço de forma acelerada, diminuindo a disponibilidade de recursos ao crescimento e desenvolvimento de plantas daninhas (Tharp \& Kells, 2001; Knezevic et al., 2003).

Os períodos críticos de interferência das plantas daninhas sobre a cultura da beterraba podem ser observados na Figura 2. Na cultura estabelecida por 40 plantas $\mathrm{m}^{-2}$ (Figura 2A), o PAI estendeu-se até 14 DAS, enquanto o PTPI prolongou-se até 36 DAS; logo, o PCPI compreende o período de 14 a 36 DAS. Na cultura estabelecida por 50 plantas $\mathrm{m}^{-2}$ (Figura 2B), o PAI estendeu-se até 24 DAS, enquanto o PTPI prolongou-se até 35 DAS; logo, o PCPI compreende o periodo de 24 a 35 DAS. Em ambos os casos, o controle das plantas daninhas deve ser realizado durante toda a extensão do PCPI para que não ocorram perdas significativas de produtividade comercial de raízes maiores que $5 \%$. Esse controle pode ser efetuado por meio de capina e/ou aplicação de herbicida seletivo.
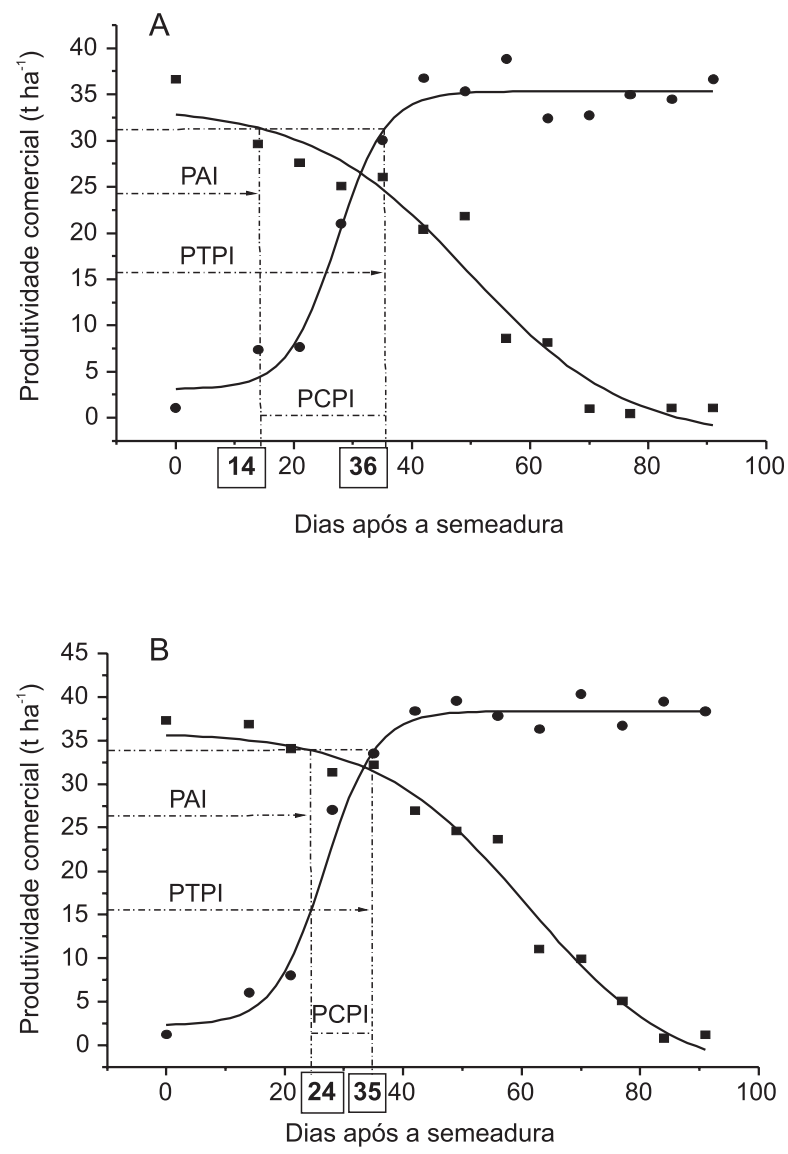

Figura 2 - Estimativa dos períodos críticos de interferência das plantas daninhas na cultura da beterraba, em função das densidades populacionais de 40 e 50 plantas $\mathrm{m}^{-2}$ (A e B, respectivamente). FCAV/UNESP, Jaboticabal, SP, 2006.

Assim, a densidade populacional de 50 plantas $\mathrm{m}^{-2}$ da cultura da beterraba proporcionou ambiente menos agressivo ao desenvolvimento da cultura em relação àquela de 40 plantas $\mathrm{m}^{-2}$. Conseqüentemente, a capacidade de supressão da cultura sobre as plantas daninhas foi maior naquela estabelecida por 50 plantas $\mathrm{m}^{-2}$, proporcionando menor crescimento da comunidade infestante, em relação àquela estabelecida por 40 plantas $\mathrm{m}^{-2}$. Esse fato pode ser evidenciado comparando-se o PCPI (11 dias) mais curto da cultura adensada com o PCPI (22 dias) mais prolongado, na densidade de 40 plantas $\mathrm{m}^{-2}$.

Segundo Pitelli \& Durigan (1984), as plantas daninhas que emergirem após o final do PCPI não atingirão crescimento suficiente para competir com a cultura, a qual estará em fase avançada do ciclo de desenvolvimento e 
terá mobilizado grande parte dos recursos necessários para completar o ciclo agrícola. Portanto, o PCPI visa o controle da comunidade infestante, antes que a interferência se instale de maneira definitiva, até o momento em que as plantas daninhas que vierem a surgir não mais interfiram na produtividade da cultura (Pitelli, 1985).

Pode-se, também, observar que o PTPI foi pouco afetado pelo adensamento, evidenciando que o controle das plantas daninhas deve ser realizado até 36 e 35 DAS, para a cultura estabelecida por 40 e 50 plantas $\mathrm{m}^{-2}$, respectivamente. Por outro lado, o PAI foi altamente afetado, passando de 14 para 24 DAS, para a cultura estabelecida por 40 e 50 plantas $\mathrm{m}^{-2}$, respectivamente, inferindo que o adensamento da semeadura permite ao produtor ter mais tempo na escolha da medida de controle a ser aplicada.

O PAI sofreu grande alteração em função da maior supressão imposta pela cultura adensada sobre a comunidade infestante, em relação àquela não-adensada. Por outro lado, observou-se pouca alteração do PTPI, embora essa supressão tenha sido maior que nos períodos crescentes de convivência. Contudo, o fato que, provavelmente, influenciou mais fortemente a determinação do PTPI foi a supressão quase total da comunidade infestante no período de 42 dias de controle, em ambas as densidades populacionais. De acordo com Pitelli (1985), o final do PTPI é definido quando a própria cultura, por meio principalmente de sombreamento, controla e impede o crescimento das plantas daninhas.
Segundo Pitelli (1985, 1987), a extensão desses períodos pode ser influenciada pela aplicação de certas práticas culturais de manejo. Como exemplo, podem-se citar a fertilização e a época de cultivo, além do arranjo espacial, entre outras.

A presença da comunidade infestante durante todo o ciclo de desenvolvimento da cultura da beterraba reduziu a produtividade comercial de raízes de 36,67 para $1,06 \mathrm{t} \mathrm{ha}^{-1}(97,11 \%)$ e de 37,33 para $1,24 \mathrm{t} \mathrm{ha}^{-1}(96,67 \%)$, evidenciando alta suscetibilidade da cultura da beterraba à interferência das plantas daninhas.

Analisando os parâmetros das equações de regressão que determinam os períodos críticos de interferência das plantas daninhas sobre a cultura da beterraba (Tabela 2), observa-se que a velocidade de perda de produtividade comercial de raízes ( $\mathrm{dx}$ nos períodos de convivência) foi maior na cultura estabelecida por 40 plantas $\mathrm{m}^{-2}(13,22 \%)$, em relação àquela estabelecida por 50 plantas $\mathrm{m}^{-2}(12,60 \%)$. Verifica-se, ainda, que a velocidade de ganho de produtividade comercial de raizes ( $\mathrm{dx}$ nos periodos de controle) foi maior na cultura estabelecida por 50 plantas $\mathrm{m}^{-2}(4,25 \%)$, comparada àquela estabelecida por 40 plantas $\mathrm{m}^{-2}(4,15 \%)$.

Isso evidencia que a produção comercial de raízes da cultura da beterraba foi afetada mais rapidamente pela presença do que pela remoção das plantas daninhas nos períodos iniciais do ciclo de desenvolvimento da cultura, em ambas as densidades populacionais. Além disso, pode-se inferir que a cultura adensada apresentou maior "potencial de resposta"

Tabela 2 - Parâmetros das equações sigmoidais de Boltzmann $\left(\mathrm{A}_{1}, \mathrm{~A}_{2}, \mathrm{x}_{0}\right.$ e dx) e coeficiente de correlação $\left(\mathrm{R}^{2}\right)$, em função da densidade populacional da cultura da beterraba. FCAV/UNESP, Jaboticabal-SP, 2006

\begin{tabular}{|c|c|c|c|c|}
\hline \multirow{2}{*}{ Boltzmann } & \multicolumn{4}{|c|}{ Densidade populacional } \\
\cline { 2 - 5 } & \multicolumn{2}{|c|}{40 plantas $\mathrm{m}^{-2}$} & \multicolumn{2}{c|}{50 plantas $\mathrm{m}^{-2}$} \\
\cline { 2 - 5 } & Convivência & Controle & Convivência & Controle \\
\hline $\mathrm{R}^{2}$ & 0,96 & 0,97 & 0,98 & 0,98 \\
\hline $\mathrm{A}_{1}$ & 33,63 & 3,08 & 35,95 & 2,32 \\
\hline $\mathrm{A}_{2}$ & $-2,32$ & 35,34 & $-3,86$ & 38,39 \\
\hline $\mathrm{x}_{0}$ & 49,75 & 27,30 & 60,93 & 26,78 \\
\hline $\mathrm{dx}$ & 13,22 & 4,15 & 12,60 & 4,25 \\
\hline
\end{tabular}


ao controle das plantas daninhas em relação àquela não-adensada, visto que apresentou menor velocidade de perda e maior velocidade de ganho de produtividade.

A supressão imposta pela cultura, promovida pelo adensamento de semeadura da cultura da beterraba, afetou a época e extensão dos periodos críticos de interferência das plantas daninhas, já que estes são estimados em função da produtividade, a qual, por sua vez, é diretamente afetada pela interferência da comunidade infestante. Esse fato pode ser evidenciado por meio da comparação dos resultados referentes ao acúmulo de massa seca pelas plantas daninhas (Figura 1), à diferença nesse acúmulo entre as duas densidades populacionais (Tabela 1) e à estimativa dos periodos críticos de interferência (Figura 2).

Embora o produtor tenha aumento no custo de instalação da cultura, sobretudo com sementes, quando estabelecer a cultura mais adensada, a produtividade possivelmente será maior. Nesse caso, a estimativa de ganho em produtividade seria, aproximadamente, de $17 \%$, caso adotasse a maior densidade populacional e os períodos de controle das plantas daninhas estimados. Da mesma maneira, os gastos com o manejo de plantas daninhas seriam menores, visto que o período em que essas plantas deveriam ser controladas foi menor quando a cultura foi adensada.

Portanto, deve-se entender a importância da correta determinação dos períodos críticos de interferência para escolher e aplicar a melhor forma de manejo da comunidade infestante e, assim, buscar redução nos custos de produção.

Segundo Buhler et al. (1992), a utilização de práticas de manejo que propiciem vantagem competitiva à cultura, como redução do espaçamento entre fileiras, permite diminuição na dose e no número de aplicações de herbicidas, reduzindo o custo de condução da lavoura e a contaminação do ambiente. Além disso, em áreas de olericultura, onde o manejo das plantas daninhas é feito muitas vezes por capina manual, a economia de tempo e mão-de-obra pode ser grande, o que reduz o custo de condução da cultura e disponibiliza tempo e mãode-obra para outras atividades.
Por fim, deve-se lembrar que os períodos críticos de interferência das plantas daninhas sobre as cultivadas variam em função de condições edafoclimáticas, tipo de solo, manejo adotado da cultura e das plantas daninhas, composição específica da comunidade infestante, época de plantio e de colheita, entre outros fatores. Assim, esses periodos devem ser determinados em todas as regiões e épocas de produção da cultura, a fim de que se possa estabelecer o correto manejo da flora invasora na cultura.

O adensamento de semeadura da cultura da beterraba proporcionou aumento na capacidade de supressão da cultura sobre a comunidade infestante, afetando o crescimento e a época e extensão dos períodos críticos de interferência das plantas daninhas, podendo ser usado como ferramenta eficaz no manejo da flora invasora.

\section{LITERATURA CITADA}

BALBINOT JÚNIOR, A. A.; FLECK, N. G.

Competitividade de dois genótipos de milho (Zea mays) com plantas daninhas sob diferentes espaçamentos entre fileiras. Planta Daninha, v. 23, n. 3, p. 415-421, 2005.

BRITO, C. E. F. Período de interferência de plantas daninhas na produção de beterraba (Beta vulgaris L.) implantada através de semeadura direta. 1994. $70 \mathrm{f}$. Dissertação (Mestrado em Fitotecnia) - Universidade Federal de Lavras, Lavras, 1994.

BUHLER, D. D.; GUNSOLUS, J. L; RALSTON, D. E. Integrated weed management techniques to reduce herbicide inputs. Agron. J., v. 84, n. 6, p. 973-978, 1992.

CHARLES-EDWARDS, D. A. Physiological determinants of crop growth. London: Academic Press, 1986. 161 p.

DEUBER, R. et al. Manejo de plantas daninhas em beterraba com metamitron e sua persistência em argissolo. Bragantia, v. 63, n. 2 , p. $283-289,2004$.

FISCHER, R. A.; MILES, R. E. The role of spatial pattern in the competition between crop plants and weeds. A theoretical analysis. Math. Biosci., v. 18, p. 335-350, 1973.

GRIME, J. P. Estrategias de adaptación de las plantas y procesos que controlan la vegetación. México, DF: Noriega, 1979. p. 79-87.

HALL, M. R.; SWANTON, C. J.; ANDERSON, G. J. The critical period of weed control in grain corn. Weed Sci., v. 40 , n. 3 , p. 441-447, 1992. 
HAY, R. K. M.; WALKER, A. J. An introduction to the physiology of crop yield. Essex: Longman Scientific \& Technical. 1989. 292 p.

HEWSON, R. T.; ROBERTS, H. A. Effects of weed competition for different periods on the growth and yield of red beet. J. Hortic. Sci., v. 48, n. 1, p. 281-292, 1973

HOCK, S. M. et al. Soybean row spacing and weed emergence time influence weed competitiveness and competitive indices. Weed Sci., v. 54, n. 1, p. 38-46, 2006

HORTA, A. C. S. et al. Interferência de plantas daninhas na beterraba transplantada e semeada diretamente. Acta Sci. Agron., v. 26, n. 1, p. 47-53, 2004

KAVALIAUSKAITË, D.; BOBINAS, È. Determination of weed competition critical period in red beet. Agron. Res., v. 4, p. 217-220, 2006. (Número especial)

KNEZEVIC, S. Z.; EVANS, S. P.; MAINZ, M. Row spacing influences the critical timing for weed removal in soybean (Glycine max). Weed Technol., v. 17, n. 4, p. 666-673, 2003.

KNEZEVIC, S. Z; WEISE, S. F.; SWANTON, C. J. Interference of redroot pigweed (Amaranthus retroflexus) in corn (Zea mays). Weed Sci., v. 42, n. 3, p. 568-573, 1994.

KUVA, M. A. et al. Períodos de interferência das plantas daninhas na cultura da cana-de-açúcar. I - Tiririca. Planta Daninha, v. 18 , n. 2, p. 241-251, 2000

MEDD, R. W. et al. The influence of wheat density and spatial arrangement on annual ryegrass, Lolium rigidum Gaudin, competition. Aust. J. Agric. Res., v. 36, n. 3, p. $361-371,1985$.

NORRIS, R. F. et al. Spatial arrangement, density, and competition between barnyardgrass and tomato: II. Barnyardgrass growth and seed production. Weed Sci. v. 49, n. 1, p. 69-76, 2001

NORSWORTHY, J. K.; OLIVEIRA, M. J. Comparison of the critical period for weed control in wide and narrow-row corn. Weed Sci., v. 52, n. 5, p. 802-807, 2004.

OLSEN, J.; KRISTENSEN, L.; WEINER, J. Effects of density and spatial pattern of winter wheat on suppression of different weed species. Weed Sci., v. 53, n. 5, p. 690-694, $2005 \mathrm{a}$

OLSEN, J. et al. Increased density and spatial uniformity increase weed suppression by spring wheat. Weed Res., v. 45, n. 4 , p. $316-321,2005$ b

OLSEN, J.; KRISTENSEN, L.; WEINER, J. Influence of sowing density and spatial pattern of spring wheat (Triticum aestivum) on the suppression of different weed species Weed Biol. Manag., v. 6, n. 3, p. 165-173, 2006.
PEREIRA, W. Manejo de plantas daninhas em hortaliças. Brasília: Embrapa-CNPH, 1987. 6 p. (Circular Técnica, 4)

PITELLI, R. A. Interferência das plantas daninhas em culturas olerícolas. In: CONGRESSO BRASILEIRO DE OLERICULTURA, 24; REUNIÃO LATINOAMERICANA DE OLERICULTURA, 1., 1984, Jaboticabal Anais... Jaboticabal: FCAV/UNESP, 1984. p. 75-87.

PITELLI, R. A. Interferências de plantas daninhas em culturas agrícolas. Inf. Agropec., v. 11, n. 129, p. 16-27, 1985.

PITELLI, R. A. Efeitos de períodos de convivência e de controle das plantas daninhas no crescimento, nutrição mineral, e na produtividade da cultura da cebola (Allium cepa L.). 1987. 140 f. Tese (Livre Docência em Ecologia) - Universidade Estadual Paulista, 1987.

PITELLI, R. A.; DURIGAN, J. C. Terminologia para períodos de controle e de convivência das plantas daninhas em culturas anuais e bianuais. In: CONGRESSO BRASILEIRO DE HERBICIDAS E PLANTAS DANINHAS, 15., 1984, Belo Horizonte. Resumos... Piracicaba: SBHED, 1984. p. 37.

PITELLI, R. A.; PITELLI, R. L. C. M. Biologia e ecofisiologia das plantas daninhas. In: VARGAS, L.; ROMAN, E. S. (Eds.). Manual de manejo e controle de plantas daninhas. Bento Gonçalves: Embrapa Uva e Vinho, 2004. p. 29-56.

SCHWEIZER, E. E. Broadleaf weed interference in sugarbeets (Beta vulgaris). Weed Sci., v. 29, n. 1, p. 128133,1981 .

SCOTT, R. K.; WILCOCKSON, S. J.; MOISEY, F. R. The effects of time of weed removal on growth and yield of sugar beet. J. Agric. Sci., v. 93, n. 3, p. 693-709, 1979.

SOARES, D. J. et al. Períodos de interferência das plantas daninhas na cultura da cebola (Allium cepa) transplantada. Planta Daninha, v. 21, n. 3, p. 387-396, 2003

THARP, B. E.; KELLS, J. J. Effect of glufosinate-resistant corn (Zea mays) population and row spacing on light interception, corn yield, and common lambsquarters (Chenopodium album) growth. Weed Technol., v. 15, n. 3, p. $413-418,2001$

TOZANI, R. et al. Interferência de plantas daninhas nas culturas da cenoura (Daucus carota) e beterraba (Beta vulgaris). In: CONGRESSO BRASILEIRO DA CIÊNCIA DAS PLANTAS DANINHAS, 21., 1997, Caxambu. Resumos... Piracicaba: SBHED, 1997. p. 390. 
TRANI, P. E. et al. Beterraba, cenoura, nabo, rabanete e salsa. In: RAIJ, B. van et al. (Eds.). Recomendações de adubação e calagem para o Estado de São Paulo. 2.ed. Campinas: IAC, 1997. p. 174. (Boletim Técnico, 100).

VAN ACKER, R. C.; SWANTON, C. J.; WEISE, S. F. The critical period of weed control in soybean (Glycine max (L.) Merr.). Weed Sci., v. 41, n. 1, p. 194-200, 1993
VELINI, E. D. Interferências entre plantas daninhas e cultivadas. In: SIMPÓSIO SOBRE HERBICIDAS E PLANTAS DANINHAS, 1., 1997, Dourados. Resumos... Dourados: Embrapa, 1997. p. 29-49.

WEINER, J.; GRIEPENTROG, H. W.; KRISTENSEN, L. Suppression of weeds by spring wheat Triticum aestivum increases with crop density and spatial uniformity. J. Appl. Ecol., v. 38, n. 4, p. 784-790, 2001. 